\title{
A COOPERAÇÃO BRASILEIRA NA ÁREA DA EDUCAÇÃO NOS PALOPS NO PERÍODO 2000-2012: PRINCIPAIS ATORES E PROJETOS
}

\author{
BRAZILIAN COOPERATION IN EDUCATION WITH PALOPS (2000-2012): \\ MAIN ACTORS AND PROJECTS
}

Danielle Regina Ullrich ${ }^{1}$ e Rosinha Machado Carrion ${ }^{2}$

Recebido em: 11/02/2013

Aprovado em: 15/10/2013

\section{RESUMO}

A partir da perspectiva da cooperação Sul-Sul para o desenvolvimento, discursivamente apresentada como um processo de parceria entre países semiperiféricos e periféricos para fins de vantagens mútuas, o presente artigo, de natureza teórica, tem por objetivo provocar a reflexão acerca dos termos em que está se dando a cooperação entre o Brasil e os Países Africanos de Língua Oficial Portuguesa (PALOPs). Para tal, apresenta os projetos e investimentos realizados pelo Brasil, nos últimos doze anos, no conjunto dos PALOPs, notadamente na área de educação, com destaque para os atores por eles responsáveis. Os dados coletados revelam que $77,45 \%$ dos projetos de cooperação brasileira na África estão sendo realizados nesses países e que a área da educação é que mais está recebendo recursos $(15,53 \%)$, alocados, principalmente, em formação profissional, alfabetização e formulação de políticas públicas para a educação. A conclusão a que se chega é que o direcionamento das ações de cooperação está em consonância com objetivos e estratégias da Política Externa Brasileira (PEB), refletindo tanto os objetivos de natureza política e econômica almejados pelo país quanto as questões de natureza cultural referentes à proximidade linguística e à matriz colonial comum ao Brasil e aos referidos países lusófonos.

Palavras-chave: Cooperação Sul-Sul; Educação; Brasil; PALOPs.

\begin{abstract}
From the perspective of South-South cooperation for development, discursively presented as a partnership process between peripheral and semi-peripheral countries for mutual benefit, this paper, theoretical, aims to provoke reflection about the terms on which are giving cooperation between Brazil and African Countries of Portuguese Official Language (PALOP). For such, it presents the projects and investments in Brazil over the last twelve years, in all the PALOPs, notably in the area of education highlighting the actors responsible for them. The data collected showed that $77.45 \%$ of the Brazilian cooperation projects in Africa, are being conducted in these countries, and the area of education that is getting more resources (15.53\%) allocated mainly in vocational training, literacy and formulation of public policies. The conclusion reached is that the orientation of the actions of cooperation is in line with objectives and strategies of Brazilian Foreign Policy (PEB), reflecting both the goals of political and economic pursued by the country as issues of cultural nature in the face the linguistic proximity and common colonial matrix referred to Brazil and Portuguese-speaking countries.

Keywords: South-South Cooperation; Education; Brazil; PALOPs.
\end{abstract}

${ }^{1}$ Mestre em Desenvolvimento Regional pela Universidade Regional de Blumenau (FURB), Brasil. Doutoranda do Programa de Pós-Graduação em Administração da Universidade Federal do Rio Grande do Sul (UFRGS) e bolsista do Conselho Nacional de Desenvolvimento Científico e Tecnológico (CNPq). E-mail: danielle_ullrich@yahoo.com.br.

${ }_{2}^{2}$ Pós-Doutora pelo Institute de Recheche Pour le Développement (2011/Université de Paris I/Sorbonne), França. Professora associada do Programa de Pós-Graduação em Administração da Escola de Administração da Universidade Federal do Rio Grande do Sul (UFRGS), Brasil. E-mail: rsmcarrion@ ea.ufrgs.br. 


\section{Introdução}

A tese da ajuda desinteressada dos países ricos e autodeclarados desenvolvidos a países por eles classificados como subdesenvolvidos, nos termos em que começou a ser praticada no período pós II Guerra Mundial, vem sendo questionada por estudiosos do campo das relações internacionais, os quais argumentam que a chamada cooperação internacional para o desenvolvimento entre países centrais e periféricos teria se constituído, historicamente, em poderosa ferramenta de dominação política e extração de benefícios econômicos.

Se, durante o período que se estende da segunda metade do século XX ao início do século XXI, as ações de cooperação internacional para o desenvolvimento foram balizadas por uma conjuntura geopolítica determinada pela bipolaridade entre dois blocos antagônicos, capitaneados pelos Estados Unidos e pela União Soviética (AYLLÓN PINO, 2007), com o fim da Guerra Fria, a globalização e o extraordinário crescimento econômico dos BRICS (Brasil, China, Índia e Rússia) e, mais recentemente, da África do Sul, as chamadas novas potências emergentes vão buscar também maior representatividade e poder no sistema internacional, o que terá implicações para o modelo de cooperação internacional (CARRION, 2012) ${ }^{3}$, até então hegemonicamente em vigor.

Dentre as estratégias adotadas pelas potências emergentes para ganhar espaço e participar das discussões e decisões sobre temas de interesse global, destacam-se práticas de cooperação que propõem relações mais igualitárias e solidárias entre os países envolvidos, as quais passam a ser identificadas sob a denominação comum de "Cooperação Sul-Sul" (CSS) Ao tratar da questão, ${ }^{3}$ Para fugir a dominação simbólica associada à palavra cooperação, parte integrante da expressão cooperação internacional para o desenvolvimento, Carrion introduz o termo "modelo", onde ter-se-ia conforme sua proposta, pelos menos dois tipos de modelo: o modelo de Cooperação proposta, pelos menos dois tipos de modelo: o modelo de Cooperação
Norte-Sul, que vigorou hegemônico até o final do século XX e o Modelo de Cooperação Sul-Sul, o qual ganha força com a luta das novas potencias emergentes por representatividade também no cenário político internacional no período recente. (CARRION, 2012).
Milani (2012) aponta que boa parte do argumento político que sustenta a CSS fundamenta-se no pressuposto de que países semiperiféricos podem e devem cooperar a fim de resolver seus próprios problemas políticos, econômicos e sociais com base em identidades compartilhadas (ex-colônias, status econômico, experiência histórica etc.), esforços comuns, interdependência e reciprocidade. Idealmente, a CSS é apresentada como um processo de parceria entre países semiperiféricos e periféricos com vistas à promoção de ganhos mútuos (PUENTE, 2010; AYLLÓN PINO, 2007; XALMA, 2011; CARRION, 2012) e que teria como uma de suas peculiaridades o reconhecimento e $\mathrm{o}$ respeito à pluralidade de saberes que permeiam as relações de troca entre países. Desse ponto de vista, as práticas e o sentido a ser atribuído ao desenvolvimento deveriam levar em consideração o passado histórico e as tradições sociais, culturais, ambientais e econômicas de cada país envolvido. Com isso, romper-se-ia com o modelo eurocêntrico, base da Cooperação Norte-Sul, que postulava, em nome do progresso e da técnica, a existência de saberes "superiores" e universais, os quais deveriam, portanto, balizar as relações de cooperação independentemente da história e das particularidades do país recebedor dos recursos de tal cooperação.

Tomando por base as iniciativas de CSS, reconhece-se a experiência brasileira como um caso privilegiado para análise. A atuação do Brasil nesse campo vem despertando atenção nos anos recentes ao evidenciar o aumento dos recursos investidos, o destino e o direcionamento de recursos para países periféricos na América Latina, África e Ásia, bem como a busca de reconhecimento como país líder no âmbito internacional ao investir e capitaniar projetos de CSS (PUENTE, 2010; VIGEVANI, CEPALUNI, 2007; VALLER FILHO, 2007; AYLLÓN PINO, 2012; MILANI, 2012). Essa situação seria reflexo tanto 
dos princípios basilares que pautam a cooperação brasileira, tais como a reconhecida tradição de respeito aos princípios da boa convivência, da cooperação e da paz entre as nações, a observância estrita das regras do direito internacional, de permanente e ativo trabalho na construção de um mundo melhor (VALLER FILHO, 2007), quanto das mudanças introduzidas no direcionamento da Política Externa Brasileira (PEB) no governo do Presidente Lula. Ressaltase que, no período 2005-2009, segundo cálculos do Instituto de Pesquisa Econômica Aplicada (IPEA), o Brasil destinou à cooperação internacional, aproximadamente, $\mathrm{R} \$ 2,9$ bilhões, distribuídos em contribuições multilaterais, programas de cooperação técnica, bolsas de estudo para estudantes estrangeiros e assistência humanitária (IPEA; ABC, 2010). Ainda conforme dados do IPEA e da Agência Brasileira de Cooperação (ABC) (2010), apenas a modalidade de concessão de bolsas de estudos para estrangeiros representou quase $10 \%$ do total da cooperação brasileira no período entre 2005 e 2009 , sendo responsável por um total acumulado de R\$284,07 milhões.

Dentre os parceiros do Brasil na CSS, destacam-se, principalmente, países da América Latina, da América Central, do Caribe e da África Lusófona, ou os PALOPs, tratados como prioridades na política externa brasileira. Dados do MRE (2007) apontam que os PALOPs somam $77,45 \%$ dos projetos de cooperação brasileira na África.

Analisando as áreas em que ocorrem os acordos de cooperação, observase a grande concentração de recursos na educação, com projetos direcionados para formação e qualificação de africanos lusófonos, diplomaticamente justificados ora em nome da proximidade com a língua e, portanto, da facilidade para a construção de "comunidades identitárias", conforme apontam Pinheiro e Beshara (2012), ora em nome da dívida histórica que o Brasil teria para com as populações africanas lusófonas devido à sua contribuição ao perfil multiétnico da nação brasileira, conforme apontam Almeida e Kraychete (2012). Questões menos aventadas dizem respeito, todavia, ao interesse econômico do Brasil na consolidação de parcerias com os PALOPs.

Nesse contexto, o presente artigo tem por objetivo contribuir para a intelegibilidade desse fenômeno, apresentando dados relativos à cooperação brasileira com os PALOPs na área de educação no período 2000-2012 e ressaltando as subáreas priorizadas nos projetos de cooperação, bem como os atores envolvidos nesse processo. Para tanto, realizou-se uma pesquisa sistemática na carteira de projetos disponibilizada pela Agência Brasileira de Cooperação (ABC) (2012) em seu sítio na internet. Foram elencados os projetos desenvolvidos pelo Brasil com Angola, Cabo Verde, Guiné-Bissau, Moçambique, São Tomé e Princípe, com a atenção voltada, especificamente, para a área de educação. Para tal, foram investigados, com base em fontes de dados secundários, dados relativos aos projetos e investimentos realizados pelo Brasil nos últimos doze anos.

Este artigo, além da presente introdução, apresenta uma breve revisão sobre o histórico da cooperação "Sul-Sul", expõe dados sobre o assunto e analisa a cooperação internacional entre Brasil e PALOPs na área de educação, apresentando, então, as considerações finais.

\section{Breve Histórico da Cooperação "Sul-Sul"}

A expressão cooperação "SulSul" (CSS), também conhecida como cooperação horizontal ou cooperação entre países em desenvolvimento ou, ainda, cooperação entre países semiperiféricos e periféricos, idealmente, é apresentada como um processo de parceria econômica, política, social e comercial ou de outra natureza que se 
estabelece trazendo vantagens mútuas para os países parceiros, semiperiféricos e periféricos, tanto de forma bilateral quanto multilateral (BUSS; FERREIRA, 2010; PUENTE, 2010; AYLLÓN PINO, 2007; XALMA, 2011).

O conceito político Sul-Sul começou a ser formulado na década de 1950, no auge da Guerra Fria. Segundo Ayllón Pino (2007), além do conflito Leste-Oeste, que caracterizou a Guerra Fria, outro conflito marcou esse período e influenciou a dinâmica da cooperação internacional para o desenvolvimento o Norte-Sul, que remonta às lutas pela independência das antigas colônias africanas nas décadas de 1940, 1950 e 1960.

A Conferência Ásia-África, realizada em Bandung, Indonésia, em abril de 1955, reuniu países avaliados como "subdesenvolvidos", para apresentarem aos países avaliados como "desenvolvidos", problemas relativos ao desenvolvimento. Formou-se, então, o Movimento dos Não Alinhados, que buscava uma reforma no sistema econômico internacional, cujo clímax ocorreu na Conferência das Nações Unidas para o Comércio e Desenvolvimento (UNCTAD), em 1964, e culminou na formação do Grupo dos 77.

Conforme Puente (2010), o Grupo dos 77 reunia países semiperiféricos e periféricos interessados em reforçar sua posição mediante a identificação de pontos de interesse comum e a proposição de medidas concretas que pudessem alterar as condições do comércio internacional, consideradas como desvantajosas para os países do Sul. O próprio modelo de cooperação para o desenvolvimento passou, também, a ser questionado, por estar assentado sobre bases ora assistencialistas ora de dominação submetidas a interesses comerciais dos países do centro.

Diante desse contexto, os diálogos, as discussões e as formações de coalizações em prol da CSS avançaram. Segundo Xalma (2011), em 1977, durante a $32^{\mathrm{a}}$ Sessão da Assembleia Geral das Nações Unidas, pela primeira vez, uma resolução adotada nessa ocasião buscou definir os objetivos da então chamada Cooperação Técnica entre Países em Desenvolvimento (CTPD) e seus princípios iniciais. A intenção era promover as alianças nacionais entre os chamados países em desenvolvimento. Em 1978, sob a égide das Nações Unidas, 138 países reuniram-se e adotaram o Plano de Ação de Buenos Aires (BAPA), cuja finalidade era promover e implementar a CTPD. Conforme Puente (2010), a Conferência de Buenos Aires representou o primeiro esforço coletivo de identificação e de sistematização das formas, modalidades e possibilidades de cooperação entre países em desenvolvimento.

De acordo com Cervo (1994) e Puente (2010), o BAPA instituiu uma nova modalidade de cooperação, a CTPD, a qual não buscava substituir os tradicionais programas de cooperação, bilaterais ou multilaterais, mas a eles acrescentar a possibilidade de cooperação técnica entre os países em desenvolvimento, permitindo que os países em desenvolvimento pudessem aproveitar suas capacidades e superar as relações de dependência existentes na tradicional cooperação Norte-Sul. Conforme Xalma (2011), o BAPA definiu a CTPD como "um processo consciente, sistemático e politicamente motivado", caracterizado pelos princípios de: não ingerência nos assuntos internos de outras nações por países cooperantes; igualdade entre os parceiros; e respeito para o nível local de desenvolvimento de cada país.

Após os avanços nas discussões relativas à CSS na década de 1970, Puente (2010) afirma que, nos anos 1980, não houve progressos devido à crise da dívida financeira, que atingiu, em especial, os países semiperiféricos que não conseguiram financiar os projetos de cooperação. Por imposição do Fundo Monetário Internacional (FMI), o período posterior à chamada "década perdida" foi acompanhado da implementação de progra- 
mas de ajustamento ortodoxos, com cortes nas despesas públicas, fazendo com que o espaço para financiar iniciativas de desenvolvimento fosse muito exíguo. Além das dificuldades econômicas, um número muito restrito de países semiperiféricos dispunha de recursos para implementar projetos de cooperação para o desenvolvimento.

A partir da década de 1990, com a aceleração da globalização, novos desafios surgiram para a CSS, instaurando a necessidade de novas formas de inserção na arena internacional para todos os países, mas, especialmente, para os semiperiféricos. A CSS seria um mecanismo inovador de interdependência com vistas a minimizar os riscos adjacentes ao processo de globalização e maximizar as oportunidades advindas desse processo. Em especial, por recomendação do Programa das Nações Unidas para o Desenvolvimento (PNUD) e também pela iniciativa de alguns países do Sul, reforçou-se o discurso da CSS nos foros internacionais, o que pôde ser percebido por meio das diversas conferências internacionais realizadas sobre o tema a partir dos anos 2000 (PUENTE, 2010).

Em 2000, foi realizada, em Havana, a I Cúpula Sul-Sul, cuja declaração final enfatizou a importância da CSS no novo milênio, bem como a relevância de se trabalhar, no contexto da globalização, por um sistema econômico internacional democrático e justo, promovendo a participação dos países semiperiféricos e periféricos nas decisões. A par disso, enfatizou-se a importância do compartilhamento de tecnologia e conhecimento entre os países do Sul, assim como a manutenção das relações entre Norte e Sul (UN, 2000).

Em dezembro de 2003, foi realizada, em Marrakesh, a Conferência de Alto Nível sobre Cooperação Sul-Sul, da qual resultaram a Declaração de Marrakesh e o Arcabouço de Marrakesh para a Implantação da Cooperação Sul-Sul. Nessa Declaração, a CSS foi apresentada como complementar à
Cooperação Norte-Sul, com o intento de contribuir para o desenvolvimento no contexto internacional, nos termos dos Objetivos do Milênio. A Declaração reconheceu, ainda, a importância da parceria entre organizações não governamentais (ONG), empresas, fundações e universidades nos projetos de cooperação internacional para o desenvolvimento. $\mathrm{O}$ documento elaborado em Marrakesh esboçou a relevância do papel desempenhado pelo setor privado nas operações conjuntas de cooperação internacional, bem como o papel das universidades em promover o intercâmbio de conhecimentos e atuar em educação e capacitação (UN, 2003).

Em junho de 2005, foi realizada, em Doha, no Qatar, a Segunda Cúpula do Sul, na qual os países reafirmaram os compromissos assumidos nas Conferências de Havana em 2000 e de Marrakesh em 2003. Ratificaram também o papel que desempenha a CSS diante dos desafios impostos aos países do Sul, em um contexto geral de multilateralismo, reconhecendo que esse tipo de cooperação é um complemento e não um substituto à tradicional perspectiva de cooperação Norte-Sul. Além disso, enfatizaram a necessidade de reforma da Organização das Nações Unidas (ONU) para assegurar uma maior participação dos países do Sul nos processos decisórios $(\mathrm{G} 77,2005)$.

Por fim, em 2009, a Assembleia Geral da ONU aprovou o documento final da Conferência de Alto Nível das Nações Unidas sobre Cooperação SulSul, que ocorreu em Nairóbi, no Quênia. O documento reforçou os princípios da Cooperação Sul-Sul e também destacou a importância da cooperação trilateral, em especial, em reconhecimento à crise financeira e econômica, ressaltando a relevância do apoio dos países desenvolvidos e dos organismos multilaterais à CSS (UN, 2009). 


\begin{tabular}{|c|c|c|}
\hline Ano & Conferência & Local \\
\hline 1955 & Conferência Ásia-África & Bandung, Indonésia \\
\hline 1964 & $\begin{array}{c}\text { Conferência das Nações Unidas para o Comércio e } \\
\text { Desenvolvimento (UNCTAD) }\end{array}$ & Genebra, Suíça \\
\hline 1978 & Conferência de Buenos Aires & Buenos Aires, Argentina \\
\hline 2000 & I Cúpula Sul-Sul & Havana, Cuba \\
\hline 2003 & $\begin{array}{c}\text { Conferência de Alto Nível sobre } \\
\text { Cooperação Sul-Sul }\end{array}$ & Marrakesh, Marrocos \\
\hline 2005 & Segunda Cúpula do Sul & Doha, Qatar \\
\hline 2009 & $\begin{array}{c}\text { Conferência de Alto Nível das Nações Unidas } \\
\text { sobre Cooperação Sul-Sul }\end{array}$ & Nairóbi, Quênia \\
\hline
\end{tabular}

Quadro 1 - Marcos Históricos da Cooperação Sul-Sul

Fonte: elaborado pelas autoras.

O traçado histórico (Quadro 1) e as discussões sobre a CSS a consolidaram como uma modalidade de cooperação que contempla três dimensões: (i) dimensão política, que promove a constituição de âmbitos autônomos para a geração de perspectivas e práticas alternativas entre países semiperiféricos e periféricos; (ii) dimensão técnica, processo pelo qual países semiperiféricos e periféricos adquirem capacidades individuais e coletivas através de intercâmbios cooperativos em conhecimentos, experiências tecnológicas, expertises tecnológicas, que se traduzem em projetos e programas de cooperação; e (iii) dimensão econômica, realizada no âmbito comercial, financeiro e de investimentos entre países semiperiféricos e periféricos (AYLLÓN PINO, 2012).

Ressalta-se que a CSS tem sido a modalidade de cooperação frisada pela política externa brasileira a partir do governo Lula, com continuidade no governo de Dilma Rousseff. Em relação às prioridades de países parceiros na modalidade CSS, o Brasil privilegia os PALOPs.

\section{Cooperação internacional na área de educação entre Brasil e PALOPs}

O mandato do Presidente Lula, iniciado em 2003, abriu um novo capítulo nas relações entre Brasil e África, combinando uma nova estratégia de inserção no sistema internacional e uma transformação social interna. Já em seu discurso de posse, Lula destacou que o continente africano seria um vetor fundamental da política externa, a qual foi autodefinida como afirmativa e propositiva. O discurso de aproximação foi reforçado com as constantes visitas de Lula ao continente africano, tendo visitado, no primeiro ano de seu mandato, São Tomé e Príncipe, Moçambique e Angola - países integrantes dos PALOPs (VISENTINI; PEREIRA, s.d; VIGEVANI, CEPALUNI, 2007).

Nesse discurso, a aproximação com os PALOPs justifica-se tanto pelo fundamento da solidariedade internacional como pela necessidade de compensação da dívida histórica com os africanos devido à sua contribuição para a formação da nação multiétnica brasileira. Além disso, outros fatores motivam a cooperação com os países africanos e não podem ser desconsiderados, tais como: a necessidade de inserção competitiva em um mercado globalizado, o apoio aos princípios democráticos como forma de adequação internacional e a necessidade de integração regional como forma de aumentar a competitividade econômica e de enfrentar desafios internos e externos resultantes de uma economia globalizada (ALMEIDA; KRAYCHETE, 2012).

Com base nessas motivações, Pinheiro e Beshara (2012) destacam a educação como um poderoso mecanismo de criação de identidade e mudança social, além de ser foro de ampla inci- 
dência política. Para eles, a educação integra a agenda da política externa em direção à construção e consolidação de novos arranjos políticos. Noutras palavras, a educação pode ser uma grande aliada da política externa dos Estados na construção de comunidades políticas, ajudando a criar uma identidade que dê sustentação às suas aspirações no reordenamento global.
Por isso, a educação é uma das áreas priorizadas pelo governo brasileiro na cooperação com os PALOPs. Segundo a ABC (2012), os PALOPs são o grupo de países em que há mais parcerias formalizadas. De acordo com MRE (2007), os PALOPs somam 77,45\% dos projetos de cooperação brasileira na África (Figura 1).

\begin{tabular}{|c|c|}
\hline País & \% de Atividades de Cooperação \\
\hline Cabo Verde & 19,52 \\
\hline Guiné-Bissau & 18,06 \\
\hline Moçambique & 17,15 \\
\hline Angola & 13,26 \\
\hline São Tomé e Príncipe & 9,46 \\
\hline Senegal & 4,66 \\
\hline Nigéria & 3,48 \\
\hline Camarões & 2,41 \\
\hline Benin & 2,07 \\
\hline Namíbia & 1,78 \\
\hline Quênia & 1,66 \\
\hline Marrocos & 1,51 \\
\hline Zimbábue & 1,05 \\
\hline TOTAL & 3,93 \\
\hline Demais países com menos de $1 \%$ & 100 \\
\hline
\end{tabular}

Quadro 2 - Cooperação Brasil - África por país.

Fonte: MRE (2007).

A cooperação brasileira com os países africanos desenvolve-se em diversas áreas (Figura 2), sendo as principais a saúde, a qualificação profissional, a agricultura, a pecuária e a educação, que juntas somam, de acordo com dados do MRE (2007), 76,99\% das atividades realizadas. A área de educação, foco deste estudo, corresponde a $15,53 \%$ dos projetos realizados entre Brasil e África.

\begin{tabular}{|c|c|}
\hline Atividade & \% das Atividades Realizadas \\
\hline Saúde & 22,42 \\
\hline Qualificação Profissional & 21,78 \\
\hline Agricultura e Pecuária & 17,26 \\
\hline Educação & 15,53 \\
\hline Desenvolvimento Social & 5,54 \\
\hline Energia e Biocombustíveis & 4,03 \\
\hline Esporte & 3,55 \\
\hline Urbanização & 3,55 \\
\hline Cultura & 1,65 \\
\hline Gerenciamento eletrônico & 1,15 \\
\hline Outros & 3,53 \\
\hline
\end{tabular}

Quadro 3 - Atividades de Cooperação Brasil - África por assunto.

Fonte: MRE (2007). 
A Divisão de Temas Educacionais do MRE, que trata de projetos de cooperação na área de educação, aponta que, através das ações de cooperação educacional, a Política Externa Brasileira age em pelo menos três frentes (MRE, 2012a):

a) Economicamente, a educação, ao relacionar-se diretamente à qualificação da mão de obra de um país, interfere no desenvolvimento econômico. No cenário de globalização, a habilidade de uma economia em atrair capitais, investimentos e tecnologias, inserindo-se de forma competitiva no mercado internacional, está condicionada ao nível educacional e à qualificação dos seus recursos humanos;

b) Politicamente, a cooperação educacional representa parte de uma agenda positiva da política externa, ao promover a aproximação entre os Estados. A visão do Brasil como um país que age com base em princípios de solidariedade e respeito favorece a formação de um pensamento positivo com relação à cooperação brasileira;

c) Culturalmente, a convivência, o aprendizado do idioma e a troca de experiências contribuem para o estreitamento de laços entre as sociedades. Com isso, tem-se a formação de uma cultura de integração e de conhecimento mútuo das realidades de outros países.

A base de dados da ABC (2012) apresenta 92 projetos executados e em execução entre o Brasil e os PALOPs, no período entre 2001 e 2012 (consideradas as datas iniciais dos projetos), conforme figura 3. Destaca-se que o maior número de projetos ocorre em Cabo Verde e sobre São Tomé e Príncipe, considerados pequenos PALOPs.

\begin{tabular}{|c|c|c|}
\hline País & $\begin{array}{c}\text { Quantidade de Projetos Bilaterais } \\
\text { com Brasil }\end{array}$ & $\begin{array}{c}\text { Período (data de início dos } \\
\text { projetos) }\end{array}$ \\
\hline Angola & 13 & $2003-2011$ \\
\hline Cabo Verde & 23 & $2004-2012$ \\
\hline Guiné-Bissau & 17 & $2003-2011$ \\
\hline Moçambique & 16 & $2001-2011$ \\
\hline São Tomé e Príncipe & 23 & $2001-2011$ \\
\hline TOTAL & 92 & $2001-2012$ \\
\hline
\end{tabular}

Quadro 4 - Projetos Bilaterais entre Brasil e PALOPs.

Fonte: Compilação de dados disponíveis em ABC (2012).

Com relação às subáreas de atuação dos projetos, a figura 4 demonstra que a maior concentração de projetos ocorre, respectivamente, na área de for- mação profissional $(61,96 \%$ dos projetos), de alfabetização $(8,7 \%$ dos projetos) e de políticas públicas $(7,61 \%$ dos projetos).

\begin{tabular}{|c|c|c|c|c|c|c|}
\hline Área/País & Angola & $\begin{array}{c}\text { Cabo } \\
\text { Verde }\end{array}$ & $\begin{array}{c}\text { Guiné- } \\
\text { Bissau }\end{array}$ & $\begin{array}{c}\text { Moçambi- } \\
\text { que }\end{array}$ & $\begin{array}{c}\text { São Tomé e } \\
\text { Príncipe }\end{array}$ & TOTAL \\
\hline Ensino Superior & 3 & 2 & 1 & 0 & 0 & 6 \\
\hline Formação Profissional & 7 & 12 & 15 & 10 & 13 & 57 \\
\hline Educação Especial & 2 & 3 & 0 & 0 & 0 & 5 \\
\hline Alfabetização & 0 & 1 & 0 & 2 & 5 & 8 \\
\hline Ensino Fundamental & 1 & 0 & 0 & 0 & 0 & 1 \\
\hline Educação a Distância & 0 & 0 & 1 & 1 & 0 & 2 \\
\hline Políticas Públicas & 0 & 3 & 0 & 2 & 2 & 7 \\
\hline Merenda Escolar & 0 & 2 & 0 & 1 & 3 & 6 \\
\hline
\end{tabular}

Quadro 5 - Classificação dos Projetos Bilaterais entre Brasil e PALOPs.

Fonte: Compilação de dados disponíveis em ABC (2012). 
O direcionamento dos projetos para a área de formação profissional está relacionado à falta de mão de obra especializada nos PALOPs. Os investimentos em capacitação da mão de obra objetivam a disponibilidade tanto de mão de obra capacitada como de mercado interno para as empresas se instalarem nesses países. Ressalta-se que, dentre os atores que influenciam as decisões sobre as ações de cooperação, estão os empresários brasileiros. Conforme apontam Visentini e Pereira (s.d), no primeiro ano à frente do governo, $\mathrm{o}$ Presidente Lula viajou à África juntamente com uma comitiva de 128 empresários interessados na expansão de exportações. Esse número cresce se for levado em consideração todo o período do governo Lula.

Os programas de alfabetização para jovens e adultos, conduzidos pela $\mathrm{ABC}$, contam com o apoio de uma ONG brasileira, a Associação de Apoio ao Programa Alfabetização Solidária (AAPAS), e estão voltados para reduzir os índices de analfabetismo dos PALOPs. Dados do PNUD (2009) apontam que, no período entre 1999 e 2007 , a taxa de alfabetização de adultos era de $83,8 \%$ em Cabo Verde, $87,9 \%$ em São Tomé e Príncipe, 67,4\% em Angola, $44,4 \%$ em Moçambique e 64,6\% em Guiné Bissau.

Com relação aos projetos voltados às políticas públicas, destaca-se o projeto "Bolsa-Escola", aplicado em Moçambique e São Tomé e Príncipe, com base nas diretrizes do modelo já utilizado no Brasil.

As diversas áreas de atuação na cooperação em educação exigem a participação de uma pluralidade de atores na execução dos projetos. Isso se dá uma vez que, por se tratarem de questões muito específicas, como formação profissional, alfabetização, ensino superior e fundamental, os diplomatas e técnicos vinculados ao Ministério das Relações Exteriores (MRE) precisam contar com a expertise de outros atores para a implementação dos projetos. No caso da cooperação em educação com os PALOPs, além da ABC, participam como instituições executoras brasileiras ministérios, universidades e institutos federais brasileiros, associações e organizações nacionais e estaduais.

\begin{tabular}{|c|c|c|c|c|c|c|}
\hline Organização/País & Angola & $\begin{array}{c}\text { Cabo } \\
\text { Verde }\end{array}$ & $\begin{array}{l}\text { Guiné- } \\
\text { Bissau }\end{array}$ & Moçambique & $\begin{array}{c}\text { São Tomé } \\
\text { e Prínci- } \\
\text { pe }\end{array}$ & $\begin{array}{l}\text { TO- } \\
\text { TAL }\end{array}$ \\
\hline MEC - Ministério da Educação & 4 & 8 & 3 & 5 & 3 & 23 \\
\hline $\begin{array}{l}\text { MRE - Ministério das Relações } \\
\text { Exteriores }\end{array}$ & 1 & 1 & 1 & 1 & 2 & 6 \\
\hline Ministério da Defesa & 0 & 0 & 2 & 0 & 1 & 3 \\
\hline $\begin{array}{l}\text { MPA - Ministério da Pesca } \\
\text { e Aquicultura }\end{array}$ & 0 & 0 & 1 & 0 & 0 & 1 \\
\hline $\begin{array}{l}\text { MAPA - Ministério da Agricultu- } \\
\text { ra, Pecuária e Abastecimento }\end{array}$ & 0 & 0 & 1 & 0 & 0 & 1 \\
\hline $\begin{array}{l}\text { MME - Ministério das Minas e } \\
\text { Energia }\end{array}$ & 0 & 0 & 1 & 0 & 0 & 1 \\
\hline $\begin{array}{l}\text { DEAF - Departamento de África } \\
\text { (Brasil) }\end{array}$ & 0 & 0 & 1 & 0 & 0 & 1 \\
\hline SENAI & 2 & 3 & 4 & 0 & 3 & 12 \\
\hline SENAI/SP & 0 & 0 & 2 & 0 & 0 & 2 \\
\hline SENAI/BA & 0 & 0 & 0 & 2 & 0 & 2 \\
\hline SENAI/PE & 0 & 0 & 0 & 0 & 2 & 2 \\
\hline SEBRAE & 0 & 0 & 1 & 0 & 0 & 1 \\
\hline SENAC & 0 & 0 & 0 & 2 & 0 & 2 \\
\hline
\end{tabular}


(continuação)

\begin{tabular}{|c|c|c|c|c|c|c|}
\hline Organização/País & Angola & $\begin{array}{c}\text { Cabo } \\
\text { Verde }\end{array}$ & $\begin{array}{l}\text { Guiné- } \\
\text { Bissau }\end{array}$ & Moçambique & $\begin{array}{c}\begin{array}{c}\text { São Tomé } \\
\text { e Prínci- } \\
\text { pe }\end{array} \\
\end{array}$ & $\begin{array}{l}\text { TO- } \\
\text { TAL }\end{array}$ \\
\hline IBGE & 0 & 1 & 0 & 0 & \begin{tabular}{l|l}
0 \\
\end{tabular} & 1 \\
\hline UNESCO & 1 & 1 & 1 & 1 & 1 & 5 \\
\hline IRBr - Instituto Rio Branco & 2 & 2 & 2 & 1 & 2 & 9 \\
\hline CAPES & 0 & 0 & 1 & 1 & 0 & 2 \\
\hline $\begin{array}{l}\text { UFSM - Universidade Federal de } \\
\text { Santa Maria }\end{array}$ & 0 & 1 & 0 & 0 & 0 & 1 \\
\hline UNB - Universidade de Brasília & 1 & 0 & 1 & 0 & 0 & 2 \\
\hline $\begin{array}{l}\text { UTFPR - Universidade Tecnoló- } \\
\text { gica Federal do Paraná }\end{array}$ & 0 & 0 & 1 & 0 & 0 & 1 \\
\hline $\begin{array}{l}\text { UFPR - Universidade Federal do } \\
\text { Paraná }\end{array}$ & 0 & 0 & 0 & 1 & 0 & 1 \\
\hline $\begin{array}{l}\text { UNILAB - Universidade da Inte- } \\
\text { gração Internacional da Lusofonia } \\
\text { Afro-Brasileira }\end{array}$ & 0 & 0 & 0 & 1 & 0 & 1 \\
\hline $\begin{array}{l}\text { UFG - Universidade Federal de } \\
\text { Goiás }\end{array}$ & 0 & 0 & 0 & 1 & 0 & 1 \\
\hline $\begin{array}{l}\text { UFJF - Universidade Federal de } \\
\text { Juiz de Fora }\end{array}$ & 0 & 0 & 0 & 1 & 0 & 1 \\
\hline $\begin{array}{l}\text { UFRJ - Universidade Federal do } \\
\text { Rio de Janeiro }\end{array}$ & 0 & 0 & 0 & 1 & 0 & 1 \\
\hline $\begin{array}{l}\text { UFF - Universidade Federal } \\
\text { Fluminense }\end{array}$ & 0 & 0 & 0 & 1 & 0 & 1 \\
\hline $\begin{array}{c}\text { UFBA - Universidade Federal da } \\
\text { Bahia }\end{array}$ & 0 & 0 & 0 & 0 & 1 & 1 \\
\hline $\begin{array}{l}\text { AAPAS - Associação de Apoio ao } \\
\text { Programa Alfabetização Solidária }\end{array}$ & 0 & 2 & 0 & 2 & 4 & 8 \\
\hline $\begin{array}{l}\text { CEFET - Centro Federal de Edu- } \\
\text { cação Tecnológica }\end{array}$ & 0 & 1 & 0 & 0 & 0 & 1 \\
\hline $\begin{array}{c}\text { IFECTG - Instituto Federal de } \\
\text { Educação, Ciência e Tecnológica } \\
\text { de Goiás }\end{array}$ & 0 & 1 & 0 & 0 & 0 & 1 \\
\hline $\begin{array}{c}\text { SEMAD/MG - Secretaria de } \\
\text { Estado de Meio Ambiente e De- } \\
\text { senvolvimento Sustentável } \\
\end{array}$ & 0 & 1 & 0 & 0 & 0 & 1 \\
\hline $\begin{array}{c}\text { SENAR - Serviço Nacional de } \\
\text { Aprendizagem Rural }\end{array}$ & 1 & 0 & 0 & 0 & 0 & 1 \\
\hline $\begin{array}{l}\text { LNCC - Laboratório Nacional de } \\
\text { Computação Científica }\end{array}$ & 1 & 0 & 0 & 0 & 0 & 1 \\
\hline $\begin{array}{c}\text { IESCOC - Instituto de Ensino } \\
\text { Superior COC }\end{array}$ & 1 & 0 & 0 & 0 & 0 & 1 \\
\hline $\begin{array}{c}\text { ANPROTEC - Associação Nacio- } \\
\text { nal de Entidades Promotoras de } \\
\text { Empreendimentos Inovadores }\end{array}$ & 1 & 0 & 0 & 0 & 0 & 1 \\
\hline $\begin{array}{l}\text { ESMPU - Escola Superior do } \\
\text { Ministério Público da União }\end{array}$ & 0 & 0 & 0 & 1 & 0 & 1 \\
\hline Missão Criança & 0 & 0 & 0 & 1 & 2 & 3 \\
\hline Radiobrás & 0 & 0 & 0 & 0 & 1 & 1 \\
\hline Instituto Lumen Brasília & 0 & 0 & 0 & 0 & 1 & 1 \\
\hline
\end{tabular}

Quadro 6 - Atores que participam da execução dos projetos com a ABC.

Fonte: Compilação de dados disponíveis em ABC (2012). 
A figura 5 demonstra a participação de outros Ministérios, além do MRE, que atuam na execução dos projetos: MRE - Ministério das Relações Exteriores (6); MEC - Ministério da Educação (23); Ministério da Defesa (3); MPA - Ministério da Pesca e Aquicultura (1); MAPA - Ministério da Agricultura, Pecuária e Abastecimento (1); e MME - Ministério das Minas e Energia (1). Ressalta-se que o MPA, o MAPA e o MME aparecem na listagem por serem instituições executoras de um único projeto intitulado "Missão de Prospecção para Elaboração de Projeto de Cooperação Técnica nas áreas de Desenvolvimento Agrário, Desenvolvimento Social, Pesca e Aquicultura, Agricultura, Minas e Energia e Educação", desenvolvido em Guiné-Bissau.

Com relação à atuação do MEC, enumeraram-se todos os projetos conectados ao Ministério, todavia, executados por órgãos e assessorias vinculados a este, como o Fundo Nacional de Desenvolvimento da Educação, a Secretaria de Educação Especial, a Secretaria de Educação Básica e a Secretaria de Educação Profissional e Tecnológica.

Outros departamentos, institutos e assessorias do governo brasileiro envolvidos com a execução dos projetos são: DEAF - Departamento de África (1); IBGE (1); Instituto Rio Branco (9); CAPES - (2); e LNCC - Laboratório Nacional de Computação Científica (1). Salienta-se que o Instituto Rio Branco vem atuando na capacitação para diplomatas dos Estados membros da Comunidade dos Países de Língua Portuguesa (CPLP).

Destaca-se, também, a participação das organizações do Sistema "S" de ensino: SENAI (12); SENAI/SP (2); SENAI/BA (2); SENAI/PE (2); SEBRAE (1) e SENAC (2). Os projetos desenvolvidos por essas organizações tem caráter de formação profissional, tanto na indústria, através da implementação dos Centros de Formação Profissional capitaneados pelo SENAI, como no comércio e serviço nos projetos im- plementados pelo SENAC.

As Universidades Federais Brasileiras e os Institutos Federais também aparecem como executores de projetos de educação: UNB - Universidade de Brasília (2); UFSM - Universidade Federal de Santa Maria (1); UTFPR - Universidade Tecnológica Federal do Paraná (1); UFPR - Universidade Federal do Paraná (1); UNILAB - Universidade da Integração Internacional da Lusofonia Afro-Brasileira (1); UFG - Universidade Federal de Goiás (1); UFJF - Universidade Federal de Juiz de Fora (1); UFRJ - Universidade Federal do Rio de Janeiro (1); UFF - Universidade Federal Fluminense (1); UFBA - Universidade Federal da Bahia (1); CEFET - Centro Federal de Educação Tecnológica (1); e IFECTG - Instituto Federal de Educação, Ciência e Tecnológica de Goiás (1). Cabe ressaltar que alguns projetos são executados por um grupo de universidades, enquanto outros têm apenas uma universidade como executora. Os projetos que envolvem as Universidades e os Institutos Federais estão voltados para o ensino superior e para a capacitação técnica. Dentre eles está a formação de professores para atuar no Ensino Básico e Médio, bem como a formação de agentes para atuar no serviço público.

Outras associações e instituições também participam como executoras dos programas, com destaque para a AAPAS - Associação de Apoio ao Programa Alfabetização Solidária (8) e a Missão Criança (3), ONGs envolvidas em projetos de cooperação internacional capitaneados pela ABC. Em nível supranacional, a Organização das Nações Unidas para a Educação, a Ciência e a Cultura (UNESCO) atuou no projeto "Oficina de Trabalho sobre Educação de Jovens e Adultos nos Países de Língua Portuguesa", que ocorreu nos cinco PALOPs.

Esse cenário demonstra que, além da $\mathrm{ABC}$, órgão oficial do governo brasileiro para assuntos de cooperação, diversos outros atores estão atuando 
na cooperação internacional na área de educação, sob os auspícios da agência, mas não necessariamente. Existem projetos de CSS que estão sendo desenvolvidos e que não constam na carteira de projetos disponibilizada pela ABC. Um exemplo é o acordo de cooperação firmado entre a UFRGS (Universidade Federal do Rio Grande do Sul) e a UniCV (Universidade de Cabo Verde) para a implementação de Cursos de Mestrado e Doutorado em Cabo Verde.

Outro exemplo são os programas coordenados pelo Ministério da Educação (MEC), como o Programa de Estudantes - Convênio de Graduação $(\mathrm{PEC}-\mathrm{G})^{4}$ e Pós-Graduação (PEC-PG) ${ }^{5}$. Dados do MEC (2012) informam que, de 2004 a 2012, ingressaram no programa PEC-G 5.319 alunos estrangeiros.

Desse modo, os dados disponibilizados pela carteira de projetos da $\mathrm{ABC}$ podem ser utilizados como base para compreender o cenário dos projetos de cooperação na área de educação entre o Brasil e os PALOPs. Esses dados refletem a postura proativa do Brasil em apoiar e implementar projetos de cooperação na área de educação, demonstrando a preocupação com a alfabetização de jovens e adultos e a formação e capacitação profissional. Tais dados refletem os interesses econômicos do Brasil nos projetos de cooperação internacional, como apontado pelo MRE (2012a). Além disso, espelham os objetivos políticos ao externar uma agenda positiva, promovendo a aproximação com os Estados periféricos e consolidando uma posição do país como protagonista no cenário multilateral. Cabe ainda ressaltar que a pesquisa apontou para a participação de outros atores na

${ }^{4}$ O Programa de Estudantes-Convênio de Graduação (PEC-G) oferece oportunidades de formação superior a cidadãos de países em desenvolvimento com os quais o Brasil mantém acordos educacionais e culturais. Desenvolvido pelos ministérios das Relações Exteriores e da Educação, en parceria com universidades públicas - federais e estaduais - e particulares, o PEC-G seleciona estrangeiros, entre 18 e 25 anos, com ensino médio completo, para realizar estudos de graduação no país. (MEC, 2012).

${ }_{5}$ O Programa de Estudantes-Convênio de Pós-Graduação (PEC-PG) criado oficialmente em 1981, oferece bolsas de estudo para nacionais de países em desenvolvimento com os quais o Brasil possui acordo de cooperação cultural e/ou educacional, para formação em cursos de pós-graduação stricto sensu (mestrado e doutorado) em Instituições de Ensino Superior (IES) brasileiras. (MRE, 2012b).
Cooperação Sul-Sul brasileira, além da tradicional atuação do governo federal e de suas agências especializadas. Isso indica o desenvolvimento de um processo de cooperação internacional descentralizada, no qual atores subnacionais participam da implementação dos projetos. Todavia, chama-se atenção para o fato de que a lista de projetos de cooperação internacional disponibilizada pela $\mathrm{ABC}$ está incompleta, uma vez que outros projetos, que não constam nessa lista, estão sendo desenvolvidos tanto por órgãos governamentais, nacionais ou subnacionais como por organizações não governamentais.

\section{Considerações Finais}

Pode-se observar, a partir do presente estudo, que a CSS se apresenta como uma proposta de cooperação internacional para o desenvolvimento, cujos ideais vem sendo amadurecidos desde a década de 1950 e que, atualmente, estão sendo incorporados na política externa de países potências emergentes, como o Brasil.

A política externa brasileira, em especial, durante o governo Lula, amadureceu o conceito político do "Sul", buscando reforçar as relações com países semiperiféricos e periféricos e aumentar o protagonismo do Brasil no cenário internacional, mediante a assunção de uma postura de país doador no campo da cooperação internacional para o desenvolvimento. Para tanto, a estratégia foi aproximar-se dos países vizinhos sul-americanos e dos PALOPs.

Os dados apresentados sobre a cooperação internacional do Brasil na área de educação demonstram que, para além da retórica, o Brasil tem investido em esforços e priorizado ações e projetos na área de educação com os PALOPs, mantendo as diretrizes da política externa aplicadas no governo Lula. No que se refere à continuidade e ao aprofundamento das ações, a PEB de Dilma Rousseff estaria mantendo os 
mesmos pressupostos e ideais que guiaram a PEB no governo anterior; todavia, seu plano de governo aponta para a intenção de maior proximidade com os países vizinhos sul-americanos e não faz referência à aproximação com os PALOPs.

Concernente às subáreas de atuação dos projetos, os investimentos estão sendo direcionados para formação profissional, alfabetização de jovens e adultos e políticas públicas. Os dados demonstram a preocupação com a formação de mão de obra nos PALOPs e a diminuição dos índices de analfabetismo entre jovens e adultos, bem como com a estruturação do sistema educacional desses países. $\mathrm{O}$ direcionamento de tais ações estaria de acordo com os objetivos econômicos do país, os quais utilizam a cooperação Sul-Sul para formar mão de obra em potenciais locais de interesse para expansão das empresas brasileiras.

Também merece atenção o componente político da inserção do tema educação na política externa brasileira dirigida aos PALOPs. Pinheiro e Beshara (2012), com base na ideia de que os projetos políticos de um Estado manifestam-se fortemente na constituição dos sistemas nacionais educacionais, concebem que, também em suas ações exteriores, os países se valham de medidas educacionais para respaldar suas estratégias e assegurar seus objetivos. Para tanto, poderiam estar empenhados na construção de comunidades identitárias, cujos elos seriam questões culturais e identitárias entre os países, reforçados pelo sistema educacional.

A maior facilidade de penetração dada à língua em comum e o uso de um discurso que exalta a parceria étnica entre o Brasil e os PALOPs são fatores que, sem dúvida, contribuem para criar um ambiente favorável aos interesses políticos e econômicos do Brasil na África. A participação de outros atores, além do MRE e do Itamaraty, na execução dos projetos de cooperação, também é uma novidade das estratégias presentes na PEB no período avaliado.
Verificou-se que tanto organizações estatais subnacionais como organizações não governamentais estão envolvidas nos projetos de cooperação Brasil-PALOPs, muitas das quais sob os auspícios da ABC. A questão que fica em aberto é o sentido, tendo-se em vista as duas hipóteses iniciais, que caracteriza essa cooperação. A primeira hipótese diz respeito a um sentido reprodutor da cultura política autoritária e discriminatória que marcou, historicamente, o campo da Cooperação Norte-Sul, tendo como pressuposto de base a superioridade técnica dos países do Norte sobre aqueles do Sul, o que daria aos primeiros o "direito" de imporem medidas, programas e projetos. E a segunda refere-se a um sentido baseado em relações mais homogêneas e no respeito à diversidade histórica, cultural e econômica dos países - caminho esse que parte da premissa de que o conhecimento é um processo dinâmico a ser coletivamente construído, desde que respeitadas as particularidades sociais, culturais, políticas e econômicas locais. Impondo-se o primeiro caminho, o Brasil estaria a implementar "pacotes prontos" e concebidos a partir da realidade brasileira no campo da educação. Valendo o segundo, privilegiar-se-iam, quando das ações de cooperação, processos de construção conjunta nas diferentes fases e etapas dos processos de formação e capacitação.

Todavia, como já referido, tratase de uma questão ainda em aberto, mas que merece investigação e análise em estudos futuros.

\section{Referências}

1. ABC - Agência Brasileira de Cooperação. Projetos. Pesquisa de Projetos. Disponível em: < http://www.abc.gov. br/abc_por/webforms/projeto.aspx?secao_id=132\&Idioma_id=1>. Acesso em $\overline{2} 0$ nov. 2012. 
2. ALMEIDA, E. L. de.; KRAYCHETE E. S.. O Discurso Brasileiro para a Cooperação em Moçambique: existe ajuda desinteressada? In: III Conferência Internacional do IESE "Moçambique: Acumulação e Transformação em Contexto de Crise Internacional". Conference Paper, Maputo, Moçambique, setembro de 2012.

3. AYLLÓN PINO, B. Transformações Globais, Potências Emergentes e Cooperação Sul-Sul: desafios para a cooperação europeia. Caderno CRH, Salvador, v. 25, n. 65, p. 233-249, Maio/Ago. 2012.

4. La Cooperación Internacional para el Desarrollo: fundamentos y justificaciones en la perspectiva de la Teoría de las Relaciones Internacionales. Carta Internacional, v. 2, n. 2, p. 32-47, out. 2007.

5. BUSS, P. M.; FERREIRA, J. R. Diplomacia da saúde e cooperação SulSul: as experiências da Unasul saúde e do Plano Estratégico de Cooperação em Saúde da Comunidade de Países de Língua Portuguesa (CPLP). Revista Eletr. de Com. Inf. Inov. Saúde. Rio de Janeiro, v.4, n.1, p.106-118, mar., 2010.

6. CARRION, R. M. Em Análise a Contribuição dos Recursos da Cooperação Internacional para o Desenvolvimento de Cabo Verde. Porto Alegre. Projeto de Pesquisa PPGa/UfRGS. Agosto 2012.

7. CERVO, A. Socializando o desenvolvimento: uma história da cooperação técnica internacional do Brasil. Revista Brasileira de Política Internacional, Brasília, v.37, n.1, p.37-63, 1994.

8. G77 - Group of 77. Second South Summit. Doha Declaration. Doha, Qatar, 12-16 Jun. 2005. Disponível em: $<$ http://www.g77.org/southsummit2/ doc/Doha\%20Declaration(English). pdf>. Acesso em: 29 nov. 2012.

9. IPEA - Instituto de Pesquisa Econômica Aplicada; ABC - Agência Bra- sileira de Cooperação. Cooperação brasileira para o desenvolvimento internacional 2005-2009. Brasília: IPEA: ABC, 2010. Disponível em: <http:// www.abc.gov.br/lerNoticia.asp?id_Noticia $=606>$. Acesso em: 21 mai. $20 \overline{1} 1$.

10. MILANI, C. R. S. Aprendendo com a História: críticas à experiência da Cooperação Norte-Sul e atuais desafios à Cooperação Sul-Sul. Caderno CRH, Salvador, v. 25, n. 65, p. 211-231, Maio/ Ago. 2012.

11. MEC. PEC-G - Números de alunos estrangeiros ingressantes no Programa. Disponível em: < http://painel.mec.gov. br/painel.php? $\operatorname{modulo}=$ principal $/ \mathrm{de}-$ talhamentoIndicador \&acao $=A \&$ detalhes $=$ pais\&indid $=328>$. Acesso em: 03 dez. 2012.

12. MRE. Divisão de Temas Educacionais. A Educação na Política Externa Brasileira. Disponível em: < http:// www.dce.mre.gov.br/PEB.html>. Acesso em: 01 dez. 2012a.

13. MRE. Divisão de Temas Educacionais. Programa de Estudantes-Convênio de Pós-Graduação - PEC-PG. Disponível: <http://www.dce.mre.gov. br/PEC/PECPG.html>. Acesso em: 01 dez. 2012b.

14. MRE. Secretariado Geral para Cooperação e Promoção Comercial. SouthSouth Cooperation Activities Carried Out By Brazil, 2007. Disponível em: < http://www.funag.gov.br/biblioteca/index.php?option $=$ com docman \& task $=$ doc_details\&gid $=4 \overline{62} \&$ Itemid $=41>$. Acesso em: 02 dez. 2012.

15. PINHEIRO, L.; BESHARA, G. Politica Externa e educação: confluências e perspectivas no marco da integração regional. In: PINHEIRO, Leticia; MILANI, Carlos (org.) Política externa brasileira: as práticas da política e a política das práticas. Rio de Janeiro: Editora FGV, 2012.

16. PNUD. Human Development Report 2009. Overcoming Barriers: hu- 
man mobility and development. New York: UNDP, 2009.

17. PUENTE, C. A. I. A cooperação técnica horizontal brasileira como instrumento de política externa: a evolução da cooperação técnica com países em desenvolvimento - CTPDno período 1995-2005. Brasília: FUNAG, 2010.

18. UN - UNITED NATIONS. Declaration of the South Summit. Havana, Cuba, 10-14 Apr. 2000. Disponível em: $<$ http://www.g77.org/doc/docs/summitfinaldocs english.pdf.> Acesso em: 23 nov. 2012.

19. UN - UNITED NATIONS. Group of 77. High-Level Conference on South-South Cooperation: Marrakech declaration on South-South Cooperation. Morocco, dez. 2003. Disponível em: <http://www.g77.org/doc/docs/ Marrakech\%20Final\%20Docs\%20(E). pdf>. Acesso em: 23 nov. 2012.

20. UN - UNITED NATIONS. High -level United Nations Conference on South-South Cooperation. Nairobi, dez 2009. Disponível em: <http://southsouthconference.org/?page_id=6>. Acesso em: 23 nov. 2012.

21. VALLER FILHO, W. O Brasil e a crise haitiana: a cooperação técnica como instrumento de solidariedade e de ação diplomática. Brasília: FUNAG, 2007.

22. VIGEVANI, T.; CEPALUNI, G. A Política Externa de Lula da Silva: A Estratégia da Autonomia pela Diversificação. Contexto Internacional, v. 29, n. 2, p. 273-335, julho/dezembro 2007.

23. VISENTINI, P. G. F.; PEREIRA, A. D. A Política Africana do Governo Lula. Disponível em: <http://www6. ufrgs.br/nerint/folder/artigos/artigo40. pdf $>$. Acesso em 26 nov. 2012.

24. XALMA, C. Report on SouthSouth Cooperation in Ibero-America 2011. Madrid: Ibero-American General Secretariat (SEGIB), 2011. 